"middle gravels") under normal glacial drift, although I have found gravels belonging to all the others so situated.

In Ireland the resurrectionists have employed very loose evidence to reinstate their "middle gravel," and from what I have seen in some places in England, very similar evidence has been used there also. After the ice and waters of the different seas disappeared from the face of the country, the latter must have been more or less destitute of a protecting envelope of vegetation; therefore meteoric abrasion had a maximum denuding power, that formed extensive sheets of a re-arranged drift. These accumulations in low places were thick, but gradually thinned as they ascended heights. This process may be seen going on at the present day in the neighbourhood of Swansea, where the sulphurous fumes from the furnaces bave destroyed vegetation, while Agassiz mentions the formation of a similar drift in Brazil. This re-arranged drift in places in Ireland has been made to do duty as "Upper Boulder-clay,". and I was shown a similar drift in Lancashire as "Upper Boulder-clay." I am very much afraid that the statement made by the President of Section C. at the late Meeting of the British Association in Bristol is too true; and that there is no one living capable of writing about the Glacial Period, as our knowledge of it and what probably took place during it is very crude. In the County Dublin there are low and high level gravels and drifts containing marine shells; and the various writers on the subject, myself among the number, have put forward more or less vague speculations and theories to account for the difference in their levels; while none of us ever thought of collecting the fossils from the different zones, and seeing if they formed similar groups. If the latter was done. I would not be surprised to hear, the groups had more or less different characters, showing the gravels to be of different ages.

\title{
VII.-A Chapter in the History of Methorites.
}

By Walter Fuígt, D.Sc., F.G.S., Of the Department of Mineralogy, British Museum.

(Continued from page 504.).

\section{Fonnd 1861.-Breitenbach, Bohemia. ${ }^{1}$}

This remarkable siderolite was found in Bohemia, at a spot not very far distant from the Saxon frontier or indeed from Rittersgrün, in Saxony, where a wass closely resembling it was almost contemporaneously found. So far back as 1751 at Steinbach, a village about midway between. Breitenbach and Rittersgrün, a meteorite in all respects similar was discovered; the three masses are so similar to one another and so dissimilar to any others preserved in collections that there can be little doubt that they belong to the same fall. In 1825 Stromeyer examined a siderolite in which he found 61.8 per cent. of silica; this also appears to have been a member of this

1 N. Story-Maskelyne. Proc. Royal Soc. 1869, xix. 266.-V. von Lang. Sitzber. Ak. Wiss. Wien, 1869, lix. 848. Pogg. Ann. cxxxix. 315.-N. Story-Maskelyne. Phil. Trans. 1871, elxi. 359.-G, vom Rath. Zeit. Deut. Geol. Gesell. Berlin, 1873, xxv. 106. Pogg. Ann. Erganz.-Bd. vi. 337. Jahrb. Mineralogie, 1874, i. 79. 
shower of meteorites, believed by Breithaupt to have been the "Eisenregen" which occurred at Whitsuntide, 1164, in Saxony, when a mass of iron fell near the town of Meissen.

A polished surface of either of these masses exhibits irregularly formed patches of nickel-iron, the interspaces being partly filled with small patches of iron sulphide, the greater portion of the surface being occupied by a greenish and greyish-brown crystalline magma. After the removal of the two first-mentioned ingredients with mercury chloride, the magma is found to consist of (1) highly crystalline, bright green or greenish-yellow grains; (2) rusty-brown, sometimes nearly black, sometimes also nearly colourless grains of a mineral presenting crystalline features, but on which definite planes are rare; and (3) crystalline grains of chromite.

The first of these ingredients is bronzite, the crystallographic characters of which are described in the paper of von Lang, who gives the results of measurements made on nine crystals; these results are mineralogically important as affording for the first time complete data for the crystallography of a rhombic mineral having the formula of enstatite. The elements of the crystal are :

$$
a: b: c=0.87568: 0.84960: 1
$$

which give the following among the important angles by calculation :

$$
\begin{aligned}
& 110,010=44^{\circ} 8^{\prime} \\
& 101,100=41^{\circ} 11^{\prime} \\
& 011,010=40^{\circ} 16^{\prime}
\end{aligned}
$$

Von Lang observed the following faces :

$100,010,001,011,054,302,101,102,103,104,410,520,210,530,110,120,250$, $130,111,121,112,122,212,133,232,124,144,324,344,524.1$

The most important zonal relations. of these faces are shown in the spherical projection appended to his paper.

The hardness of this mineral is 6 and the specific gravity 3.238 , a number differing but slightly from those determined by Stromeyer and estimated by Rumler in the case of the silicates of the Steinbach siderolite. The composition of the bronzite, as determined by analyses made by the new method of distillation already alluded to (page 408) and by fusion with alkaline carbonates, was found to be:

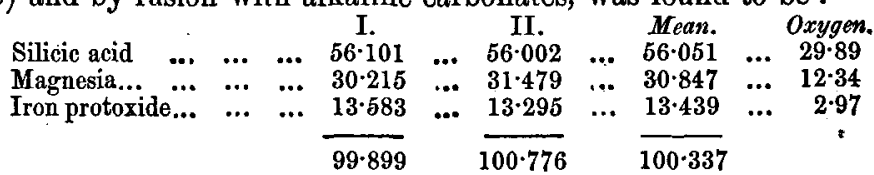

These numbers correspond very closely with the formula ( $\mathbf{M g}_{\frac{4}{5}} \mathrm{Fe}_{\frac{1}{5}}$ ) $\mathrm{SiO}_{3}$. This bronzite, which occurs in association with nickel-iron, contains only half the amount of iron met with in the bronzite of the Manegaum meteorite (page 403), which stone contains next to no nickel-iron. Rammelsberg ${ }^{2}$ has recently pointed out the fact

1 About the time that von Lang published these results vom Rath measured some crystals of terrestrial bronzite, found in a sanidine bomb from the Laachersee, and arrived at results which accord very exactly with those of von Lang. (Pogg. Ann., exxxviii. 529.)

2 C. Rammelsberg. Pogg. Ann., cxl. 311. Rammelsberg draws attention to the remarkable accordance between the angles of bronzite and olivine, which would explain the fact of G. Rose having regarded the silicate in the siderolites of Rittersgrün and Steinbach as olivine. (See note to page 313.) 
that in Stromeyer's paper, already alluded to, the specific gravity of the silicate is given $=3.27$; and he shows that, although the mineral analysed by Stromeyer contained undecomposed silicate, or more probably asmanite, the ratio of $\mathrm{F}_{\theta}$ to $\mathrm{Mg}$ is the same as in the above analyses.

By treating with hydrochloric acid the dark-coloured grains constituting the second ingredient of the meteorite and forming about one-third of the mass of the mixed silicates the iron staining them is removed, and they are left in a state of colourless purity. This mineral, to which Maskelyne has given the name asmanite, ${ }^{1}$ is silicic acid, possessing the specific gravity of quartz after fusion, and crystallising in forms belonging to the orthorhombic system. The grains of asmanite are very minute and much rounded, and, although entirely crystalline, they very rarely present faces offering any chance for a result with the goniometer; from several thousand little grains comprised in some two grammes of material Maskelyne obtained a very few crystals with sufficiently distinct crystallographic features to be available for measurement. He found the parametral ratios of asmanite to be:

$$
a: b: c=1 \cdot 7437: 1: 3 \cdot 3120
$$

The angles, as calculated from these data and as found on seven different crystals, are as follow :

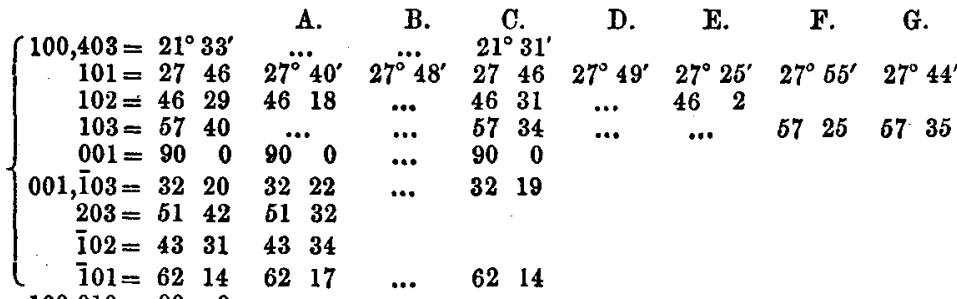

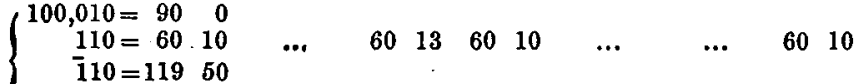

$$
\begin{aligned}
& \begin{array}{llllllllll}
110,1 \overline{1} 0=120 & 20 & \ldots & 120 & 23 & \ldots & \ldots & \ldots & 120 & 10
\end{array} \\
& \left\{\begin{array}{rrrrrrr}
001,011=73 & 12 & & & & & \\
010 & =90 & 0 & \ldots & \ldots & 90 & 0
\end{array}\right. \\
& \{101,110=63 \quad 53 \quad \ldots . \quad \ldots . .6354
\end{aligned}
$$

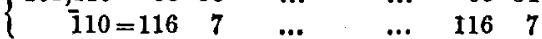

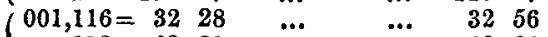

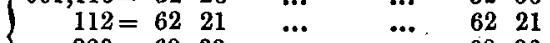

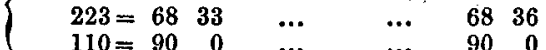

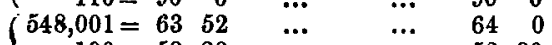

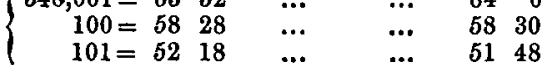

The cleavage-plane 001 has a vitreous lustre, that on the planes of the forms 100 and 101, as also of the rounded surface in the zone with them, is usually resinous, recalling the lustre of opal. The

1 Asman is the Sanscrit term, corresponding to the Greek k $_{\kappa \mu w \nu}$, for the thunderDolt of Indra. 
faces of the octaid forms are almost invariably rounded. The optical characters confirm the measurements in showing asmanite to be rhombic, the optic axes being very distinct and widely separated; their apparent angle, as measured in air, is $107^{\circ}$ to $107^{\circ} 30^{\prime}$.

The hardness of this mineral is 5.5 , and the specific gravity 2.245 ; according to vom Rath 2.247. Of the following analyses, I. and II. are the original analyses given in Maskelyne's paper, III. are the results of a recent analytical examination by vom Rath :

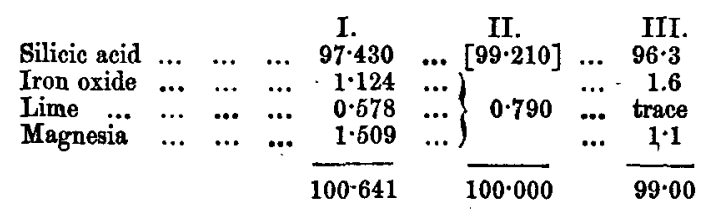

It is not a little curious to find that in his Catalogue of the Vienna Collection Partsch ${ }^{1}$ describes a specimen of the Steinbach meteorite as "native iron, jagged and hackly, with quartz in grains, and a yellow fluorspar." The detection by $G$. Rose of quartz in the oxidised crust of the Toluca iron is the only earlier instance recorded of the occurrence of free silica in a meteorite. The solvent action of an aqueous solution of sodium carbonate on asmanite and quartz in powder appears to be uniform.

As regards the relation in which the three forms of crystallised silicic acid stand to each other in respect to the mode of their formation, vom Rath remarks that while crystals of quartz have in most cases unquestionably separated from aqueous solution, and tridynite, as a characteristic mineral of the druses of volcanic rocks, appears to require the co-operation of vapour for its formation, we have probably in asmanite silicic acid crystallised from a molten mass which has become solid. Crystallised silica has not yet been produced by fusion; when it is, it will probably have the characters of asmanite.

The nickel-iron of this siderolite exhibits figures when etched, and consists of :

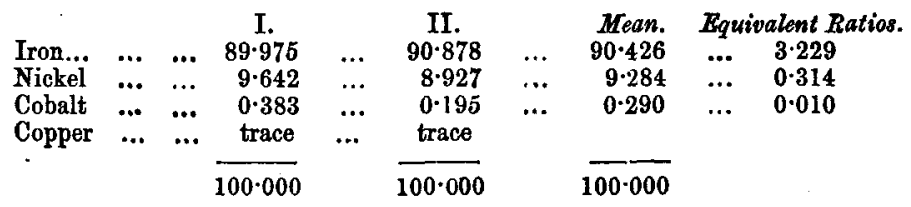

The above ratios differ but slightly from $\mathrm{Fe}:(\mathrm{Ni}, \mathrm{Co})=10: 1$. Rube's examination of the Rittersgrün iron yielded very similar per-centage numbers. The chromite of this siderolite gives angles corresponding to a regular octahedron.

1 P. Partsch. Die Meteoriten im k. k. Hof-Mineralien-Kabinette zu Wien. 1843. Page 95. 


\title{
Found 1861.-Cranbourne, near Melbourne, Australia.
}

\author{
[Lat. $38^{\circ} 11^{\prime}$ S. ; Long. $145^{\circ} 20^{\prime}$ E.] ${ }^{1}$
}

This enormous bloek of meteoric iron, which is a familiar object to those frequenting the British Museum, is, with the exception of the recently found Ovifak irons, preserved at Stockholm and Copenhagen, the largest meteorite contained in any collection. The minerals composing it have for some time past formed the subject of an investigation, and the results which I have obtained will shortly be published. It will suffice here to state that the Australian, like the Greenland irons, oxidises on exposure to moist air and scales off. These masses differ in that the Uvifak iron yields a rusty-brown coarse powder, apparently without structure; in the débris of the Australian iron, on the other hand, distinct crystals of nickel-iron are to be met with. Though partially converted into oxide and readily broken when handled, they attain after treatment with an excess of hydrogen at a red heat their pristine stability. A num.ber of crystals, apparently tetrahedra, of nickel-iron, large and very perfect, as well as plates of what may possibly be beam-iron and which lie, though not immediately, upen them, were reduced by this method: $I$ had the honour of showing a small suite of them at the Soiree of the Royal Socjety on the 26th May last. Between these two forms lie excessively thin plates of an alloy of iron, much richer in nickel, and to the diminished action of an etching fluid on this more stable alloy I ascribe the development of such thin lines as are seen in the section of the Toluca iren (see Plate IX. p. 311). The descriptions and analyses of these and other minerals will appear in the memoir which. I have in preparation. I have now to refer the reader to von Haidinger's early notices ${ }^{2}$ of the discovery of this block, based for the most part on a report supplied by Neumayer, at that time Direetor of the Flagstaff Observatory at Melboume. Two masses of meteoric iron were discovered, and near the larger meteorite Neumayer found a brown ochrey mineral which be regarded as a portion of its oxidised crust. It had but feeble action on the magnet and did not fuse before the blowpipe, but turned black and became magnetic. The hardness is rather less than that of felspar, and the specific gravity $=3 \cdot 744$; the composition, according to a recently published analysis by Haushofer, is :

\begin{tabular}{|c|c|c|c|c|}
\hline Insoluble silicate & & & & $4 \cdot 1$ \\
\hline Silicic acid & $\ldots$ & $\ldots$ & $\ldots$ & $2 \cdot 3$ \\
\hline Alumina ... & ... & $\ldots$ & $\ldots$ & $1 \cdot 5$ \\
\hline Iron oxide & $\ldots$ & $\ldots$ & $\ldots$ & $71 \cdot 1$ \\
\hline Nickel oxide & ... & $\ldots$ & $\ldots$ & $3 \cdot 1$ \\
\hline Lime $\quad \ldots$ & $\ldots$ & $\ldots$ & $\ldots$ & $1 \cdot 8$ \\
\hline Phosphorie acid & ... & $\ldots$ & .. & 1.4 \\
\hline Water ．.. & ... & ... & $\ldots$ & \\
\hline
\end{tabular}

1 K. Haushofer. Jour. Prakt. Chem., 1869, cvii. 330.-M. Berthelot. Ann. chim. et phys. 1873, xxx. 419.

2 W. von Haidinger. Sitzber. Ak. Wiss. Wien, 1861, xliii. 583 ; xliv. 378 and 465 ; and 1862, xlv. 63 . 
The author suggests that more or less rounded masses of nickeliferous göthite or limonite having a similar origin may probably be met with in the older sedimentary rocks.

In continuation of his valuable researches on the native and artificial varieties of carbon, ${ }^{1}$ Berthelot examined a specimen of the graphite-like carbon, which I found among the fragments of metal detached from this iron. His object was to ascertain which variety of carbon it resembled, whether it should be classed with the graphite of pig-iron, native plumbago, the amorphous carbon obtained by treating carbides of iron or manganese with acid, the so-called artificial graphite of the gas-retorts which he had previously shown to be no true graphite, anthracite, or, lastly, the carbonaceous substance found in the remarkable meteorite which fell at Orgueil (1864, May 14th).2

The carbon of the Cranbourne meteorite was warmed with nitric acid to remove the iron sulphide, and then digested with fuming nitric acid and chlorate of potash. After two treatments with these powerful oxidising agents, Berthelot obtained a greenish graphitic oxide, identical in every respect with the oxide obtained from the graphite of cast iron, and differing as entirely from the oxidised product which plumbago yields under like conditions. As this meteoric carbon resembles in all respects the variety of this element which has been dissolved in molten iron and separated from the solidified mass after very rapid cooling, Berthelot suggests that its formation and association with the meteoric form of iron sulphide ${ }^{3}$ may be ascribed to the action of sulphide of carbon on incandescent iron, since the carbon of the last-mentioned sulphide by decomposition is also liberated in the graphitic form. The carbon of this meteoric iron owes its present form to exposure to a very high temperature; it cannot have been produced by the action of iron on carbonic oxide or from carbon once combined with the metal and liberated at ordinary temperatures by the solution of the iron in some reagent; and is still further removed from the other variety of meteoric carbon occurring in the stone of Orgueil. The carbon of the Ovifak iron (see page 120) has likewise been examined by Berthelot. He finds it to differ so completely in its behaviour with oxidising reagents from the carbon of the Australian iron that he does not hesitate to pronounce the conditions under which these two forms of the element were produced to have been essentially distinct.

1 M. Berthelot. Ann. de Chim. et de Physique, xix. 405.

Wöhler and Cloez have found that certain of the carbonaceous meteorites contain compounds of carbon, hydrogen, and oxygen, resembling the last residues of organic substances of terrestrial origin. By applying his method of hydrogenation to the carbonaceous matter of the Orgueil meteorite, he succeeded in forming a notable quantity of a hydrocarbon of the series $\left(\mathbf{C}_{2 n} \mathbf{H}_{2 n}+2\right)$ comparable with the oils of petroleum. This new analogy between the carbonaceous matter of meteorites and substances of organic origin oceurring in the crust of our planet is of great interest. (Compt. rend., lxvii. 849.)

3 Troilite in large nodules is abundantly present in this meteorie iron. 


\section{Fell 1862.-Victoria West, Cape Colong, S. Africa.'}

This mass is of interest as belonging to the very small class or meteoric irons the fall of which was witnessed. It is stated to be shaped like a pear, the one end being smooth and rounded, the other and smaller end being jagged in a manner which indicates the probability of its having been detached from a larger meteorite.

In 1870 the mass, which weighed $6 \frac{1}{2}$ lbs., was sawn in two by order of the authorities of the South African Museum at Cape Town, and the one half further divided for distribution.

Tschermak has already shown that the meteorites of Ilimaë (see page 77) and Jewell Hill (see pages 77 and 501) enclose lamellæ of troilite, which are situated parallel to the faces of the cube; he now finds this iron furnishes a third example of this structure. The section of the iron is not only traversed by fissures, which were evidently once filled with troilite and in many cases still enclose traces of that mineral, but perfect plates of the sulphide are likewise observed. As in the former instances, the troilite lamellæ lie parallel to the faces of the cube, and are enclosed in a shell of beam. iron (kamacite). The etched figures are very distinct, and nodules of granular troilite are also met with.

Dr. L. Smith also directs attention to these fissures, and finds the figures developed by etching to be of that class where the lines are delicate and straight, inclined at a considerable angle to each other, a form common in irons rich in schreibersite. The latter mineral is diffused through the iron in masses with straight boundaries, $\frac{5}{8}$ in. to $\frac{3}{4}$ in. long, and $\frac{1}{8}$ in. in breadth, also in much narrower and longer forms, as well as in others which are triangular and arrow-shaped.

In a drawing accompanying his paper we have an interesting illustration of the specimen which he examined. In the centre of the section a cavity is seen, $1 \frac{1}{2} \mathrm{in}$. in the longest and 1 in. in the shortest diameter, the interior of which is also coated with a layer of schreibersite $\frac{1}{2} \frac{1}{0}$ th in. thick; the rest of this cavity is stated to be filled with pyrites. In his later paper, however, the nodule is said to consist of the monosulphide, troilite. In the absence of the knowledge of any test, whether with chemical reagents or with the magnet, having been applied, it appears not improbable that some of the elongated enclosed masses described above as schreibersite may be the lamellæ of sulphide which Tschermak observed.

The specific gravity of this iron is $7 \cdot 692$, and the composition :

$$
\begin{gathered}
\text { Iron }=88.83 ; \text { Nickel }=10.14 ; \text { Cobalt }=0.53 ; \text { Phosphorus }=0.28 ; \\
\text { Copper }=\text { trace. } \text { Total }=99.78 .
\end{gathered}
$$

\section{Found 1862.-Howard Co., Indiana. ${ }^{3}$}

This mass of meteoric iron, which weighs 4 kilog. and has an irregular elongated oval form, was found in a bed of stiff clay about two feet below the surface. It is one of the class of irons which is

1 G. Tschermak. Mineralogische Mittheilungen, 1871, 109.- J. L. Smith. Amer. Jour. Sc., 1873, v. 107, and 1874, vii. 394.-See also G. R. Gregory. Grou. MAg. 1868 , v. 531 .

2 J. L. Smith. Amer. Jour. So., 1874, vii. 391. 
only slightly affected by atmospheric agency, freshly cut surfaces retaining their brightness perfectly. The specific gravity of the iron is 7.821 and the composition:

Iron $=87.02 ;$ Nickel $=12.29 ;$ Cobalt $=0.65 ;$ Phosphorus $=0.02 ;$ Copper $=$ trace. Total $=99 \cdot 98$.

An etched surface does not give the slightest indication of Widmanstättian figures; their occurrence in short appears to be an exception rather than the rule in the case of irons containing more than 9 or 10 per cent. of iron (see page 80).

Dr. L. Smith, while seeking for a satisfactory explanation of the formation of these figures, expresses his belief that we shall not arrive at a satisfactory explanation until our knowledge of the effect of the presence of a minute quantity of foreign substances in iron is better understood. He alludes to the power iron, containing one per cent. or even a less amount of phosphorus, acquires of withstanding the action of acid, as evidenced in vessels used for parting gold and silver. During the crystallization of iron, as of other substances, "there is a tendency to eliminate foreign constituents to the exterior portion of the crystals": after a blast-furnace, for example, has been chilled and the metal has slowly passed from a plastic to a solid condition, the iron will be found in large crystals containing a very much smaller amount of carbon than is usually the case. If meteoric iron then be rapidly brought to the solid state, we can conceive of such a diffusion of the phosphorus as would give no marked indications in any part of the mass; by slow cooling; however, we might expect a more or less complete elimination of the phosphorus in certain parts representing the spaces between the crystals of the mass. "The portions of the iron forming the limits of the crystals become more richly charged with phosphorus," the homogeneous character of the "iron" is destroyed, and this would render its different parts variously susceptible to the action of an etching fluid.

The irons of Victoria West, South Africa (see above), and Tazewell Co., which enclose nodules of troilite and schreibersite, contain, the former only a trace of sulphur and 0.28 per cent. of phosphorus, the latter 0.016 per cent. of phosphorus; and in the mass of the Arva iron, which is filled with layers of schreibersite, there remains only 0.019 per cent. of phosphorus. The geologist and mineralogist have noticed such a segregation in a vast number of instances.

1863, March 16th.-Pulsora, N.E. of Rutlam, Indore, in Central India. ${ }^{1}$

In his descriptive catalogue of the meteorites in the Vienna Collection, which is dated 1st October, 1872, Tschermak describes this stone as chondritic, and as consisting of olivine and bronzite with nickel-iron. It occupies a place between those marked $C w$ (white rock without spherules) and $C g$ (grey rock with light-coloured spherules). The letters $C i b$, affixed to it in the catalogue, denote that it has a brecciated structure like the meteorites of Dacca and St. Mesmin.

1 G. Tschermak. Mineralogische Mittheilungen, 1872, 165. 


\section{[1863.]-South-Eastern Missouri. ${ }^{1}$}

Shepard describes a small mass of meteoric iron originally weighing about $12 \mathrm{oz}$. which was found by Prof. Shumard in 1863 in the collection of the old Western Academy of Sciences of St. Louis; the only locality given on the label is "S. E. Missouri." Shepard finds it to resemble most closely the irons of Arva and Cocke Co. The specific gravity is $7 \cdot 015-7 \cdot 112$. The metal encloses so large a quantity of schreibersite that after prolonged treatment with acid that mineral projects in thick laminæ from the surface, as mica does from coarse-grained weathered granite. The intermediate areas are not traversed with the delicate lines of the same substance (?) as in the case of other irons. The meteorite has the following composition :

Iron $=92 \cdot 096 ;$ Nickel $=2 \cdot 6.04 ;$ Schreibersite $=5 \cdot 000 . \quad$ Total $=99 \cdot 700$. with traces of cobalt, chromium, phosphorus, magnesium, carbon and silicium.

\section{Found 1864.-Wairarapa Valley, Province of Wellington, New Zealand.}

I have to thank Dr. Hector, F.R.S., Director of the Geological Survey of New Zealand, for a short account of the only meteorite which has yet been found in that colony, and which is preserved in the Colonial Museum at Wellington. It is in the form of an irregular six-sided pyramid, 7 inches high and 6 inches across the base; the edges are rounded, and the sides slightly convex and indented with shallow pits. The capacity of the stone is 49 cubic inches, the weight $480 \mathrm{oz}$., and the specific gravity 3.254 ; the hardness 5-6. It is strongly magnetic, but exhibits no decided polarity. The surface is of a light rusty brown colour, and is stained with exudations of iron chloride and sulphate. A freshly fractured surface is dark grey, mottled with bright metal-like particles of what may be iron monosulphide. By treatment with copper sulphate, the presence of iron in the form of metal was determined; with hydrochloric acid sulphuretted hydrogen was evolved, sulphur set free, and a large quantity of gelatinous silicic acid separated. The insoluble portion consisting of silica and insoluble silicates constituted 56.0 per cent. of the stone. In the soluble portion the predominating ingredients were iron, amounting to 24.01 per cent. and magnesia along with nickel, manganese and soda; alumina and chromium are not present. These reactions so far indicate in the New Zealand meteorite the presence of olivine and an insoluble silicate, in addition to nickeliron and what may be troilite or magnetic pyrites. A short notice of this stone is to be found in the Appendix A to the Jurors' Report of the New Zealand Exhibition of 1865, p. 410 . Von Haidinger alludes to the circumstances attending the fall of a meteorite of this date (Sitzber. Ak. Wiss. Wien, lii. 151).

${ }^{1}$ C. U. Shepard. Amer. Jour. Sc., 1869, xlvii. 233. In the catalogue of the Vienna Collection this iron bears the date 1864 . 


\section{5, May 23rd. - Gopalpur, Bagerhaut, Jessore, India. ${ }^{1}$}

In his paper communicated to the Vienna Academy Tschermak gives the history of the fall of this stone ${ }^{2}$ from which it appears that its descent was unattended by the detonation which usually accompanies the descent of a meteorite. The stone, of which three views are given in Tschermak's paper, has a greyish brown colour; when laid on the largest flat surface it has approximately a tra. pezoidal boundary, the upper side being curved and exhibiting pits and striped markings. The front surface (die Brustseite) is covered with a thin feebly lustrous crust which is finely striped and chan. nelled; thec hannels have a radiate arrangement and converge to a point near which is a small deep pit, while not far removed from it is another deeper-lying hollow; all the pit-like depressions are elongated, the extension being more marked the shallower they become and the further they lie from the point of radiation. It will be evident from this that during the transit of the meteorite through the atmosphere this point was in front. (See the Tucson iron, page 499.) The heat generated by the compression of the air melts the surface of the stone, and the attrition of particles of air with the more porous portion of the front surface forms the depressions radiating from the foremost point; the fused drops as fast as formed are driven off by the opposing air and give rise to the fine radiated texture of the crust. The hinder surface has very different characters: it consists of two almost flat faces meeting nearly at right angles and forming sharp edges with the front surface. Along this edge the very distinctive crust of the front surface slightly overlaps the hinder portion, terminating in a well-defined and sometimes fringed border. Here the crust is verrucose, most of the granules consisting of fused matter, many enclosing unaltered grains of the meteorite; few follow the radiated arrangement observed in the former case.

As regards the structure of the stone of Gopalpur it closely resembles, in the diminutive size of its chondra, the meteorites of Pegu and Utrecht. They are of three kinds : 1). The most striking have a brownish-grey hue and fibrous fracture, their optical principal sections being parallel and perpendicular to the direction of the fibres; these appear to be bronzite; 2). The next have a radiate strvicture, and are built up of larger bar-like transparent crystals, which in one spherule were observed to radiate from two centres; these are not improbably a felspar; and 3). The last kind of chondra consist of a granular fissured mineral which appears to be olivine.

The spherules have the same composition as their matrix, bronzite, olivine, nickel-iron and magnetic pyrites forming the predominating constituents in each case. While the chondra, met with in terrestrial rocks, in perlite, obsidian, pitchstone, in many diorites, are radiatefibrous, those occurring in meteorites are but rarely so, and in these cases the arrangement of the fibres within the spherule is excentric. Moreover, while the meteoric chondra, as already stated, consist of

1 G. Tschermak. Sitzber. Akad. Wiss. Wien, 1872, lxv. 135. Mineralogische Mittheilungen, 1872, 95.-A. Exner. Mineralogische Mittheilungen, 1872, 41.

2 Proc. Asiat. Soc. Bengal, 1865, 94.

DECADE II.-VOL. II.-No. XI. 
the same ingredients as the matrix, and often differ from it only in being more coarsely granular, the chondra of terrestrial rocks are shown by the microscope to be differently constituted from the matrix. Tschermak is of opinion that in the case of the meteorites solid masses have been reduced to powder by mutual attrition, the tougher particles withstanding the action becoming rounded, and that dust and spherules have undergone subsequent segregation.

The stone of Gopalpur consists, according to Exner's analysis, of :

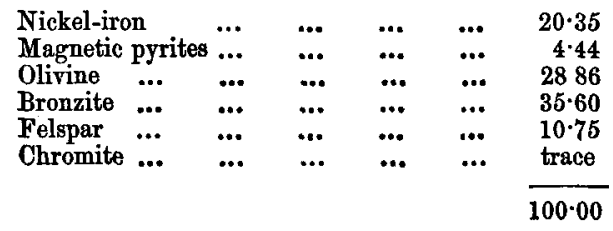

The nickel-iron has the following composition :

Iron $=90 \cdot 37 ;$ Nickel $=9 \cdot 11 ;$ Cobalt $=0.52$. Total $100 \cdot 00$. and the portions separated by acid :
A. Soluble...... $38 \cdot 31$

$\begin{array}{lllll}\mathrm{SiO}_{2} & \mathrm{Al}_{2} \mathrm{O}_{3} & \mathrm{FeO} & \mathrm{MnO} & \mathrm{CaO} \\ 38 \cdot 31 & 0 \cdot 54 & 25 \cdot 72 & - & 0 \cdot 72 \\ 57 \cdot 95 & 5 \cdot 19 & 10 \cdot 03 & 0.57 & 3 \cdot 04\end{array}$

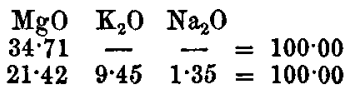
B. Insoluble.
$\begin{array}{llll}5 \cdot 19 & 10.03 & 0.57 & 3.04\end{array}$

This, it will be seen, is ono of the few meteorites containing a variety of felspar, which in this instance amounts to more than 10 per cent. Tschermak was unable to determine by an examination of microscopic sections whether it was oligoclase.

\section{5, Angust 25th.-Sherghotty, near Gya, Berar, India. ${ }^{1}$}

According to Lumpe's analysis, given below, this meteorite consists almost exclusively of silicates, only a trace of metallic iron and a very small amount of sulphur having been met with. It contains :

$$
\begin{aligned}
& \begin{array}{lllllll}
\text { Silicic acid } & \ldots & \ldots & \ldots & \ldots & \ldots & 50.21
\end{array}
\end{aligned}
$$

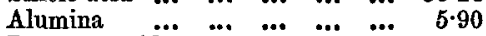

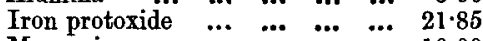

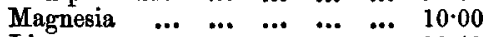

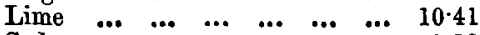

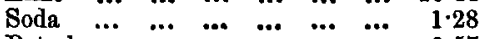

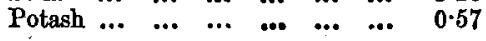

$$
\begin{aligned}
& 100 \cdot 22
\end{aligned}
$$

These results show that the Sherghotty stone belongs to the class including the meteorites of Stannern, Juvinas, and Jonzac. The stone examined by Crook in Wöhler's laboratory contained more than nine per cent. of nickel-iron and very little lime, from which it is apparent that what Crook held to be the meteorite of Sherghotty is a specimen of another fall.

1 E. Lumpe. Mineralogische Mittheilungen, 1871, 55.-G. Tschermak, Mineral ogische Mittheilungen, 1871, 56; and 1872,87; Sitzber. Ak. Wiss. Wien, 1872, lxv. 122; Jahrbuch fïr Mineralogie, 1872,733.-See also F, Crook. On the Chemical Constitution of the Ensisheim, Mauerkirchen, Sherghotty, and Muddoor Stones. Inaug.-Dissert.) 1868. Gottingen: E. A. Huth. 
More recently this meteorite has been submitted to a very complete investigation by Tschermak. He finds a fractured surface to be distinctly granular; the grains are of nearly equal magnitude, and among them the eye readily dîstinguishes two minerals : one of a light brown colour and with very distinct cleavage, the other transparent and with a strong vitreous lustre. Further microscopic and chemical examination revealed the presence of three more ingredients : a yellow silicate rarely met with and forming grains, $0.1 \mathrm{~mm}$. across, which exhibit doubly refractive power and appear to crystallise in the rhombic system; they are probably bronzite. Magnetite and magnetic pyrites were likewise present.

An augitic mineral, the one above alluded to, forms the chief mass of the stone; it has a greyish-brown colour, and exhibits double refraction with slight pleochroism. The cleavage and optical characters suggest its classification with diopside. The analytical results given below, however, show that it cannot be regarded as a member of the augite group:

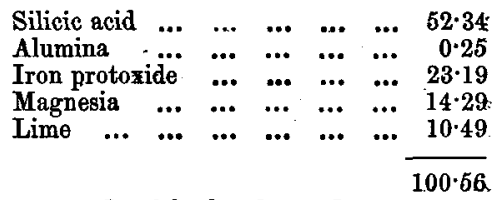

These numbers accord with the formula :

$$
\mathrm{CaO}, 2 \mathrm{MgO}, 2 \mathrm{FeO}, 5 \mathrm{SiO}_{2} \text {. }
$$

A mixture of hypersthene and hedenbergite; the former greatly preponderating, possesses such a composition. Tschermak finds, however, that the silicate cannot be thus constituted, and he considers this augitic constituent of the Sherghotty meteorite to be a chemical compound which has not yet beer discovered in our terrestrial rocks.

The second constituent of this stone occurs more sparsely in transparent colourless granules with vitreous lustre and conchoidal fracture; they proved to be distorted octahedra. "Maskelynite," as Tschermak has named this mineral, does not doubly refract light, and agrees in point of composition with no known cubic mineral, approaching nearest to a labradorite from Labrador examined some time since by Tschermak. The composition of this mineral is:

$$
\begin{array}{lllllllr}
\text { Silicic acid } & \ldots & \ldots & \ldots & \ldots & \ldots & 56.3 \\
\text { Alumina } & \ldots & \ldots & \ldots & \ldots & \ldots & \ldots & 25 \cdot 7 \\
\text { Lime } & \ldots & \ldots & \ldots & \ldots & \ldots & \ldots & 11 \cdot 6 \\
\text { Soda } & \ldots & \ldots & \ldots & \ldots & \ldots & \ldots & 5 \cdot 1 \\
\text { Potash } & \ldots & \ldots & \ldots & \ldots & \ldots & \ldots & 1.3 \\
& & & & & & & \frac{100 \cdot 0}{10}
\end{array}
$$

In comparing maskelynite with labradorite, or suggesting a possible dimorphism of labradorite, the one form triclinic, the other cubic, the fact must not be lost sight of that labradorite already represents a mixture of two silicates, anorthite and albite, which substances, it will have to be assumed, are dimorphous and occur as a 
mixture in the cubic form. The action of acid on maskelynite pointed to its composite nature, to the possibility of its consisting of an aluminous silicate containing soda which is less readily acted upon than another aluminous silicate containing lime.

Tschermak represents the Sherhgotty meteorite as made up of:

\begin{tabular}{|c|c|c|c|c|c|c|}
\hline & & Pyroxene. & Maskelynite. & Magnetite. & $\begin{array}{c}\text { Total } \\
\text { Composition } \\
\text { (Caleulated). }\end{array}$ & $\begin{array}{c}\text { Total } \\
\text { Composition } \\
\text { (Observed). }\end{array}$ \\
\hline Silicic acid & .. & $38 \cdot 21$ & $12 \cdot 68$ & - & 50.89 & 50.21 \\
\hline Alumina ... & $\ldots$ & $0 \cdot 18$ & $5 \cdot 79$ & & 5.97 & $5 \cdot 90$ \\
\hline Iron protoxide & & 1693 & 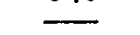 & - & $16 \cdot 93$ & $17 \cdot 59$ \\
\hline Magnesia... & ... & $10 \cdot 43$ & - & - & $10 \cdot 43$ & $10 \cdot 00$ \\
\hline Lime $\quad \ldots$ & $\ldots$ & $7 \cdot 65$ & $2 \cdot 60$ & $\ldots$ & 10.25 & $10 \cdot 41$ \\
\hline Soda $\quad \ldots$ & $\ldots$ & & $1 \cdot 14$ & - & $1 \cdot 14$ & $1 \cdot 28$ \\
\hline Potash $\quad .$. & $\therefore$ & - & 0.29 & & 0.29 & 0.57 \\
\hline Magnetite & $\ldots$ & - & & $\mathbf{4} \cdot 50$ & $4 \cdot 50$ & $4.5 \%$ \\
\hline & & & $22 \cdot 50$ & $4 \cdot 50$ & $100 \cdot 40$ & $100 \cdot 53$ \\
\hline Specific gravit & ty. & & $2 \cdot 65$ & $5 \cdot 0$ & $3 \cdot 285$ & $3 \cdot 277$ \\
\hline
\end{tabular}

While the Sherghotty stone by its peculiar oonstitution defies in a way proper classification, it finds a place among the small group of eukritic meteorites, and resembles most closely that of Petersburg (1855, August 5th).

\section{Found 1866.-Frankfort, Franklin Co., Kentucky. \\ [Lat. $38^{\circ} 14^{\prime} \mathrm{N}$.; Long. $\left.80^{\circ} 40^{\circ} \mathrm{W}.\right]^{1}$}

This block of meteoric iron, which was found on a hill 8 miles S.W. of Frankfort, was conveyed to a blacksmith's forge in that town, in order to test its quality as iron. It weighs 24 lbs., has a somewhat globular form and a highly crystalline structure. The specific gravity of this iron is $7 \cdot 692$ and the oomposition:

Iron $=90.58 ;$ Nickel $=8.53 ;$ Cobalt $=0.36 ;$ Phosphorus $=0.05 ;$ Copper, trace. Total $=99 \cdot 62$.

(To be concluded in our next Number.)

\section{NOTICES OF MEIMOIRS.}

Paper Read before the British Association at Bristol, August, 1875, Section C. Geology.

I.-ON the Distribution of the Graptolites in the Lower Ludlow Rocks, near Ludlow. By John Hopkinson, F.L.S., F.G.S.

T1HE author first drew attention to the special interest attaching 1 to the Ludlow Rocks, in connexion with investigations on the vertical distribution of the Graptolites, as being the formation in which they apparently die out.

The Rhaв Dophora or true graptolites, which with the CtadopHora or dendroid forms, are found in infinite variety when they first appear in the Arenig rocks, genera the most complex coming in simul. taneously with simpler forms, were stated to be represented in the Lower Ludlow rocks by but a single genus, Monograptus; and the Cladophora also by one genus only, Ptilograptus.

1 J. L. Smith. Amer. Jour. Sc., 1870, xlix. 331. 